\title{
OPTIMUM UNIT COMMITMENT SOLUTION OF A POWER SYSTEM BASED ON SALP SWARM ALGORITHM
}

\author{
${ }^{*}$ Marwan A. Mahmood ${ }^{1} \quad$ Kassim A. Al-Anbarri ${ }^{1}$
}

1) Electrical Engineering Department, College of Engineering, Mustansiriyah University, Baghdad, Iraq

\begin{abstract}
This paper presents an algorithm to solve the unit commitment problem in a power system. The proposed algorithm employs the Salp swarm algorithm technique to search the optimum unit schedule for a particular daily demand pattern and specific time horizon. Different constraints are taken into consideration, transition cost (start-up and shut down lcost, mean-up time, mean-down time, spinning reserve, and power balance. The proposed algorithm is applied to 10-units and 26-unit. The obtained results are compared with other methods. It reveals the robustness of the proposed algorithm in terms of minimizing overall running costs.
\end{abstract}

Keywords Unit Commitment, Salp Swarm Algorithm, Minimum Operating Cost, Load Demand

\section{Introduction}

The change in human lifestyle and the tremendous development in large industrial projects in recent years are among the factors that have led to an increase in electrical energy consumption. Under these circumstances, energy companies and investors are struggling to meet the evolution of energy consumption by making a trade-off between maintaining an adequate security margin and supplying the power with a low operational cost. To this end, an optimum unit commitment is aimed to support such activities. Based on a particular load forecast, the objective of optimum unit commitment analysis is to determine the commitment schedule of start-up and shut-down of generating units over a specific time horizon to match the forecasted load with minimum operation cost. The time horizon of the analysis may be carried out daily ( 24 hours) or every week (126 hours) [1].

Generally, there are two types of constraints to be satisfied in solving the unit commitment problem UCP. The first kinds of these constraints are related to the power system such as transmission restrictions and power reserve restrictions which will be required in case of a sudden increase in demand or the generator disconnection from the power system due to emergency conditions. The second kinds of constraints are related directly with generating units such as slope limit, slope limit, and limit Lowest to highest and downtime [2].

UCP is a nonlinear optimization problem. In the past five decades, UCP has been addressed with different approaches. One of these approaches is the traditional optimization techniques such as priority list [3][4], dynamic programming.[5], Lagrange relaxation technique [6][7], branching and delimiting approaches [8], and mixedinteger linear program [9]. Other researchers have tackled the problem from a stochastic point

*Corresponding Author: adnan.marwan378@gmail.com 
of view[10]. Artificial intelligence techniques have been applied for solving UCP, evolutionary Programming [11], simulated annealing [12] particle swarm optimization [13], Genetic Algorithm (GA) [14], hybrid PSO, Grey Wolf Optimizer (PSO-GWO)[20], Particle Swarm Optimization (PSO) [21], priority list based evolutionary algorithm (PLEA) [25] and Ant Colony Search Algorithm (ACSA) [19

This paper presents an optimum solution for the unit commitment problem based on Salp Swarm Algorithm [SSA], a proposed optimization technique, was used to solve the unit commitment problem for a 10-unit power system and a 26-unit power system. Mirjalili and colleagues proposed this algorithm in 2017[15]. It's a bio-inspired algorithm based on the salps' behavior. One of the benefits of this algorithm is that it can solve both uni-modal and multimodal functions equally well. The structure of the paper is as follows: The problem formulation is given in section 2. An overview of the Salp swarm algorithm is presented in section3. In Section 4, the application of the proposed algorithm to a typical system is described with the result obtained. The conclusion drawn by the proposed algorithm is given in section5.

\section{Problem Formulation}

\subsection{Objective Function}

The main objective of the unit commitment study is to reduce the total operating cost (fuel cost) and transitions costs (start-up and shutdown) costs of generating units in a power system over time while adhering to all restrictions. The mathematical equation for minimizing total costs can be formulated as in the form [16]:

$$
\begin{aligned}
& P C_{\text {total }}=\sum_{t=1}^{T} \sum_{g=1}^{N}\left[f_{g k}\left(p_{g k}\right)+S T C_{g k}(1-\right. \\
& \left.\left.U_{g(k-1)}\right)+S D C_{g k}\left(1-U_{g k}\right)\right] U_{g k}
\end{aligned}
$$

The fuel cost function of the unit can be expressed as a second-order function as shown:

$f_{g k}\left(p_{g k}\right)=a_{g} p_{g k}^{2}+b_{g} p_{g k}+c_{g}$

A thermal generation unit is not connected to the grid until the steam reaches a certain temperature and pressure, which increases the plant's performance. The fuel input to the unit from cold to the level that it can be connected to the grid produces no electric energy but is incredibly important, which is referred to as start-up cost. The startup cost is not fixed since it is determined by the unit's initial state. The start-up cost is highest if the unit was previously in a cold state. The start-up cost is much lower if the unit was recently turned off and is already close to running temperature and pressure the first one is known as cold start-up cost and the second is known as a banking start-up cost. The two types of start-up costs are described as follows:

$S T C_{g k}\left\{\begin{array}{l}H S C_{g} \text { if } M D T_{g} \leq T_{g}^{o f f} \leq M D T_{g}+C S H_{g} \\ C S C_{g} \text { if } T_{g}^{o f f}>M D T_{g}+C S H_{g}\end{array}\right.$

\subsection{The Constraints}

The objective function of a unit's commitment must meet a list of restrictions, which can be classified into two types:

\subsubsection{System constraints}

System constraints or maybe called coupling constraints, The coupling constraints are related to the system conditions and all the generators that state $\mathrm{ON}$ in-service) :

2.2.1.1 The sum of the generator's output power $\left[\mathrm{P}_{\mathrm{gk}}\right]$ must be equivalent to the load demand $\left[\mathrm{LD}_{\mathrm{k}}\right]$ at each period:

$\sum_{g=1}^{N} P_{g k} U_{g k}=L D_{k}$

2.2.1.2 Spinning reserves are to deal with emergency and sudden disturbances that 
occur in the power system, such as (interruption of generation and transmission lines or an unexpected increase in load demand), and it must be dealt with quickly to avoid problems in the electrical system or to deal with the scheduled plans of the system such as (maintenance operations Planned for generating units or transmission lines and for a certain period. therefore, The power reserve is being used to substitute for a reduction in the amount of power delivered:

$$
\sum_{g=1}^{N} P_{g}^{\max } \cdot U_{g k} \geq L D_{k}+S R_{k}
$$

\subsubsection{Generator constraints}

Generator constraints or maybe called local constraints, it is related to generators conditions and classified into:

\subsubsection{1 the power output of each generation unit} must be within the maximum and minimum value of generator capacity, this constraint can be expressed as follow:

$$
P_{g}^{\max } \geq P_{g k} \geq P_{g}^{\min }
$$

2.2.2.2 Minimum Up-time $\left[\mathrm{MUT}_{g}\right]$ and minimum Down-time [MDT $\left.{ }_{\mathrm{g}}\right]$ restriction: Once committed or decommitted, the unit cannot be turned ON or OFF immediately. The minimum downtime constraints specify the number of periods that must take before the unit's status can be changed $T_{g}^{o n} \geq M U T_{g}$ $T_{g}^{\text {off }} \geq M D T_{g}$

\section{Salp Swarm Algorithm [SSA]}

Complex optimization problems are commonly solved using swarm intelligence algorithms. In 2017 a new meta-heuristic algorithm was presented by Mirjalili et al[15]. called the Salp Swarm Algorithm. Salps, which are members of the salpidae tribe, have a translucent body and resemble jellyfish; some scientists have discovered that it has a feature in swarming, which is the unique behavior of the subspecies. They attributed this behavior to the ability of the breeds to achieve better mobility and foraging, In the deep seas, salps almost create swarms known as salp chains. As seen in Figure 1, the salp chain population is split into two groups: leaders and followers. The leader is the first in the swarm, following the food source and guiding the rest of the swarm's followers.

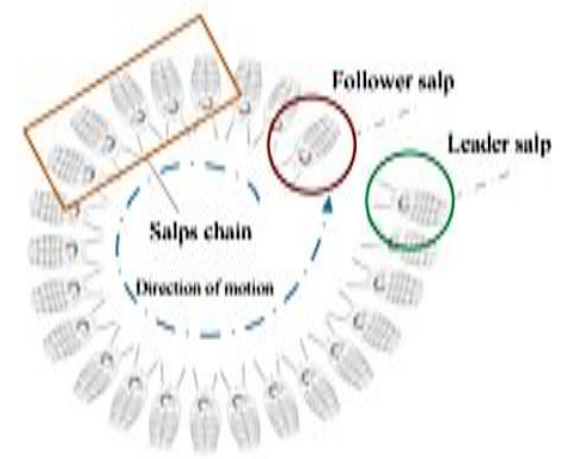

Figure 1. Illustration of salp's chain and the concept of leader and follower [24]

The position of all salps is saved in a twodimensional matrix known as $\mathrm{X}$. The SSA algorithm assumes that there is a food source called $F$ in the search space as the swarm target. The positions of salps can be represented as shown [15]:

$X_{j}^{1}\left\{\begin{array}{l}F_{j}+c_{1}\left(\left(u b_{j}-l b_{j}\right) * c_{2}+l b_{j}\right) \text { if } c_{3} \leq 0.5 \\ F_{j}-c_{1}\left(\left(u b_{j}-l b_{j}\right) * c_{2}+l b_{j}\right) \text { if } c_{3}>0.5\end{array}\right.$

The parameters $c_{2}$ and $c_{3}$ are random numbers that are uniformly generated in the range $[0,1]$. They determine the size of each step and the direction of the movement, positive or negative. The coefficient $c_{1}$ is the most important parameter in SSA. The equation that balances exploration and exploitation is: 
$c_{1}=2 e^{-\left(\frac{4 t}{\text { itermax }}\right)^{2}}$

Where itermax. is maximum iterations and $t$ is the current iteration. According to newton's motion law follower salps update position as:

$X_{j}^{i}=\frac{1}{2} a t^{2}+v_{0} t^{*}$

Where:

$\mathrm{j} \geq 2$

$\mathrm{X}_{\mathrm{j}}^{\mathrm{i}}$ : position of $\mathrm{i}$-th follower salps in $\mathrm{j}^{\text {th }}$ dimensions.

$\mathrm{t}^{*}$ : time.

$\mathrm{v}_{0}$ : Initial velocity

$\mathrm{a}=\frac{\mathrm{v}_{\text {final }}}{\mathrm{v}_{0}}$

$v=\frac{x-x_{0}}{t}$

Since time in the optimization process denotes iteration, the variance between iterations equals 1 , and considering $\mathrm{v}_{0}=0$, Equation (11) can be rewritten as follows:

$$
X_{j}^{i}=\frac{1}{2}\left(X_{j}^{i}+X_{j}^{i-1}\right)
$$

The algorithm and flowchart of Salp Swarm Algorithm SSA are shown in Fig2.

\subsection{Correlation between SSA and Problem statement:}

The number of variables denotes the total number of generating units. Each search agent (salp) represents the random allocation of power output among different generating units to meet the load demand. A number of such salps constitute the population. Here, $\mathrm{ub}_{\mathrm{j}}$ and $\mathrm{lb}_{\mathrm{j}}$ are the maximum and minimum generation capacities of generators. The food source $F$ is the best fitness (minimum cost) value among all the fitness values calculated using Eq. (1). $F_{j}$ represents its distribution among all the generators. The allocated load demand among the generators for the first population is amended by Eq. (9). For the rest of the population, it is done by Eq. (14).
Algorithm of Salp Swarm Algorithm [SSA]

Initialize a swarm of salp $x_{i}(\mathrm{i}=1,2, \ldots \ldots \ldots \ldots, \mathrm{n})$

While (iteration condition is not meet) do

Calculate the fitness of each salp in swarm

Set $\mathrm{F}$ as a position of best salp

Update $c_{1}$ by Eq. (10)

For (each salp $\left.\left(x_{i}\right)\right)$ do

If $\mathrm{i}==1$ then

Update leader position by Eq. (9)

else

Update leader position by Eq. (14)

end if

end for

check and return salps if go beyond $u b$ and $l b$ bonds end while

Return F

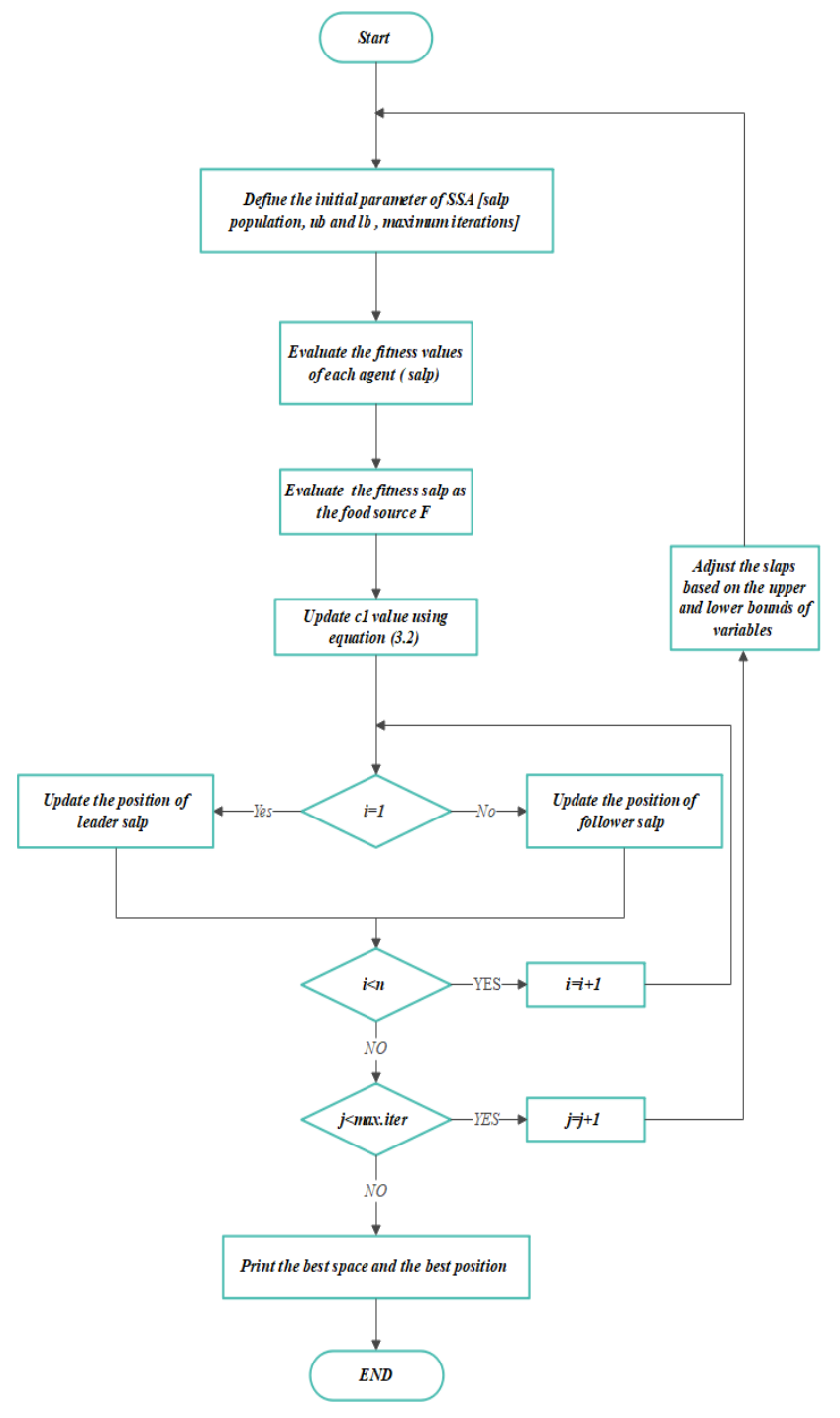

Figure 2. Flowchart of SSA 


\section{Results}

Simulations are performed using the MATLAB of the test systems that consists of 10 - units and 26-units at a 1-day time with $10 \%$ spinning reserve for this horizon time.

\subsection{Power system with 10 -units}

The number of population and maximum iterations are 20 and 100 respectively for system 10-unit that achieve minimum cost. In this case, the spinning reserve is specified as $10 \%$ from load Figure 3 shows the cost convergence characteristics. Table 1 shows demand load for $24 \mathrm{~h}$ and Table 2 is clarifying the data and parameters of 10 generation units [3]. Table 3 represents the output power and scheduling of the generator and the total operation cost obtained by applying the salp swarm algorithm is (563937 \$/day) and computation time was (42.23 sec.) It represents the minimum operating cost for the system at $24 \mathrm{~h}$ time horizon, as shown in table 4.
Table 1. load demand for 10 -unit generation

\begin{tabular}{c|ccc}
\hline Hour & LD [MW] & Hour & LD [MW] \\
\hline 1 & 700 & 13 & 1400 \\
2 & 750 & 14 & 1300 \\
3 & 850 & 15 & 1200 \\
4 & 950 & 16 & 1050 \\
5 & 1000 & 17 & 1000 \\
6 & 1100 & 18 & 1100 \\
7 & 1150 & 19 & 1200 \\
8 & 1200 & 20 & 1400 \\
9 & 1300 & 21 & 1300 \\
10 & 1400 & 22 & 1100 \\
11 & 1450 & 23 & 900 \\
12 & 1500 & 24 & 800 \\
\hline
\end{tabular}

Table 2. Data and parameters of 10-unit generation

\begin{tabular}{c|ccccccccccc}
\hline & $\begin{array}{c}P_{\max } \\
(\mathrm{MW})\end{array}$ & $\begin{array}{c}P_{\min } \\
(\mathrm{MW})\end{array}$ & $\begin{array}{c}a_{g} \\
(\$ / \mathrm{h})\end{array}$ & $\begin{array}{c}b_{g} \\
(\$ / \mathrm{MWh})\end{array}$ & $\begin{array}{c}c_{g} \\
\left(\$ / \mathrm{MW}^{2} \mathrm{~h}\right.\end{array}$ & $\begin{array}{c}\mathrm{MUT} \\
(\mathrm{h})\end{array}$ & $\begin{array}{c}\text { MDT } \\
(\mathrm{h})\end{array}$ & $\begin{array}{c}\text { HSC } \\
(\$)\end{array}$ & $\begin{array}{c}\text { CSC } \\
(\$)\end{array}$ & $\begin{array}{c}\text { CS } \\
\mathrm{H} \\
(\mathrm{h})\end{array}$ & $\begin{array}{c}\text { In. } \\
\text { stat } \\
(\mathrm{h})\end{array}$ \\
\hline Unit 1 & 455 & 150 & 1000 & 16.9 & 0.00048 & 8 & 8 & 4500 & 9000 & 5 & 8 \\
Unit 2 & 455 & 130 & 970 & 17.26 & 0.0003 & 8 & 8 & 5000 & 10000 & 5 & 8 \\
Unit 3 & 130 & 20 & 700 & 16.6 & 0.002 & 5 & 5 & 550 & 1100 & 4 & -5 \\
Unit 4 & 130 & 20 & 680 & 16.5 & 0.0021 & 5 & 5 & 650 & 1120 & 4 & -5 \\
Unit 5 & 162 & 25 & 450 & 19.7 & 0.0039 & 6 & 6 & 900 & 1800 & 4 & -6 \\
Unit 6 & 80 & 20 & 370 & 22.026 & 0.00071 & 3 & 3 & 170 & 340 & 2 & -3 \\
Unit 7 & 85 & 25 & 480 & 27.74 & 0.00079 & 3 & 3 & 260 & 520 & 2 & -3 \\
Unit 8 & 55 & 10 & 660 & 25.92 & 0.0041 & 1 & 1 & 30 & 60 & 0 & -1 \\
Unit 9 & 55 & 10 & 665 & 27.27 & 0.0022 & 1 & 1 & 30 & 60 & 0 & -1 \\
Unit 10 & 55 & 10 & 670 & 27.79 & 0.0017 & 1 & 1 & 30 & 60 & 0 \\
\hline
\end{tabular}




\begin{tabular}{|c|c|c|c|c|c|c|c|c|c|c|c|c|c|}
\hline $\mathrm{H}$ & Combination & Unit1 & Unit2 & Unit3 & Unit4 & Unit5 & Unit6 & Unit7 & Unit8 & Unit9 & Unit10 & load & $\mathrm{R}$ \\
\hline 1 & 1100000000 & 455 & 245 & 0 & 0 & 0 & 0 & 0 & 0 & 0 & 0 & 700 & 210 \\
\hline 2 & 1100000000 & 455 & 295 & 0 & 0 & 0 & 0 & 0 & 0 & 0 & 0 & 750 & 160 \\
\hline 3 & 1100100000 & 455 & 370 & 0 & 0 & 25 & 0 & 0 & 0 & 0 & 0 & 850 & 247 \\
\hline 4 & 1100100000 & 455 & 455 & 0 & 0 & 40 & 0 & 0 & 0 & 0 & 0 & 950 & 122 \\
\hline 5 & 1101100000 & 455 & 390 & 0 & 130 & 25 & 0 & 0 & 0 & 0 & 0 & 1000 & 202 \\
\hline 6 & 1111100000 & 455 & 360 & 130 & 130 & 25 & 0 & 0 & 0 & 0 & 0 & 1100 & 232 \\
\hline 7 & 1111100000 & 455 & 410 & 130 & 130 & 25 & 0 & 0 & 0 & 0 & 0 & 1150 & 182 \\
\hline 8 & 1111100000 & 455 & 455 & 130 & 130 & 30 & 0 & 0 & 0 & 0 & 0 & 1200 & 132 \\
\hline 9 & 1111111000 & 455 & 455 & 130 & 130 & 85 & 20 & 25 & 0 & 0 & 0 & 1300 & 197 \\
\hline 10 & 1111111000 & 455 & 455 & 130 & 130 & 162 & 33 & 25 & 0 & 0 & 0 & 1400 & 152 \\
\hline 11 & 1111111100 & 455 & 455 & 130 & 130 & 162 & 73 & 25 & 10 & 0 & 0 & 1450 & 157 \\
\hline 12 & 1111111111 & 455 & 455 & 130 & 130 & 162 & 80 & 25 & 10 & 10 & 10 & 1500 & 162 \\
\hline 13 & 1111111110 & 455 & 455 & 130 & 130 & 162 & 33 & 25 & 43 & 10 & 0 & 1400 & 152 \\
\hline 14 & 1111111100 & 455 & 455 & 130 & 130 & 85 & 20 & 25 & 10 & 0 & 0 & 1300 & 197 \\
\hline 15 & 1111100000 & 455 & 455 & 130 & 130 & 30 & 0 & 0 & 0 & 0 & 0 & 1200 & 132 \\
\hline 16 & 1111100000 & 455 & 310 & 130 & 130 & 25 & 0 & 0 & 0 & 0 & 0 & 1050 & 277 \\
\hline 17 & 1111100000 & 455 & 260 & 130 & 130 & 25 & 0 & 0 & 0 & 0 & 0 & 1000 & 332 \\
\hline 18 & 1111100000 & 455 & 360 & 130 & 130 & 25 & 0 & 0 & 0 & 0 & 0 & 1100 & 232 \\
\hline 19 & 1111100000 & 455 & 455 & 130 & 130 & 30 & 0 & 0 & 0 & 0 & 0 & 1200 & 132 \\
\hline 20 & 1111111100 & 455 & 455 & 130 & 130 & 162 & 33 & 25 & 10 & 0 & 0 & 1400 & 152 \\
\hline 21 & 1111111000 & 455 & 455 & 130 & 130 & 85 & 20 & 25 & 0 & 0 & 0 & 1300 & 197 \\
\hline 22 & 1100111000 & 455 & 455 & 0 & 0 & 145 & 20 & 25 & 0 & 0 & 0 & 1100 & 137 \\
\hline 23 & 1100010000 & 455 & 425 & 0 & 0 & 0 & 20 & 0 & 0 & 0 & 0 & 900 & 90 \\
\hline 24 & 1100000000 & 455 & 345 & 0 & 0 & 0 & 0 & 0 & 0 & 0 & 0 & 800 & 110 \\
\hline
\end{tabular}

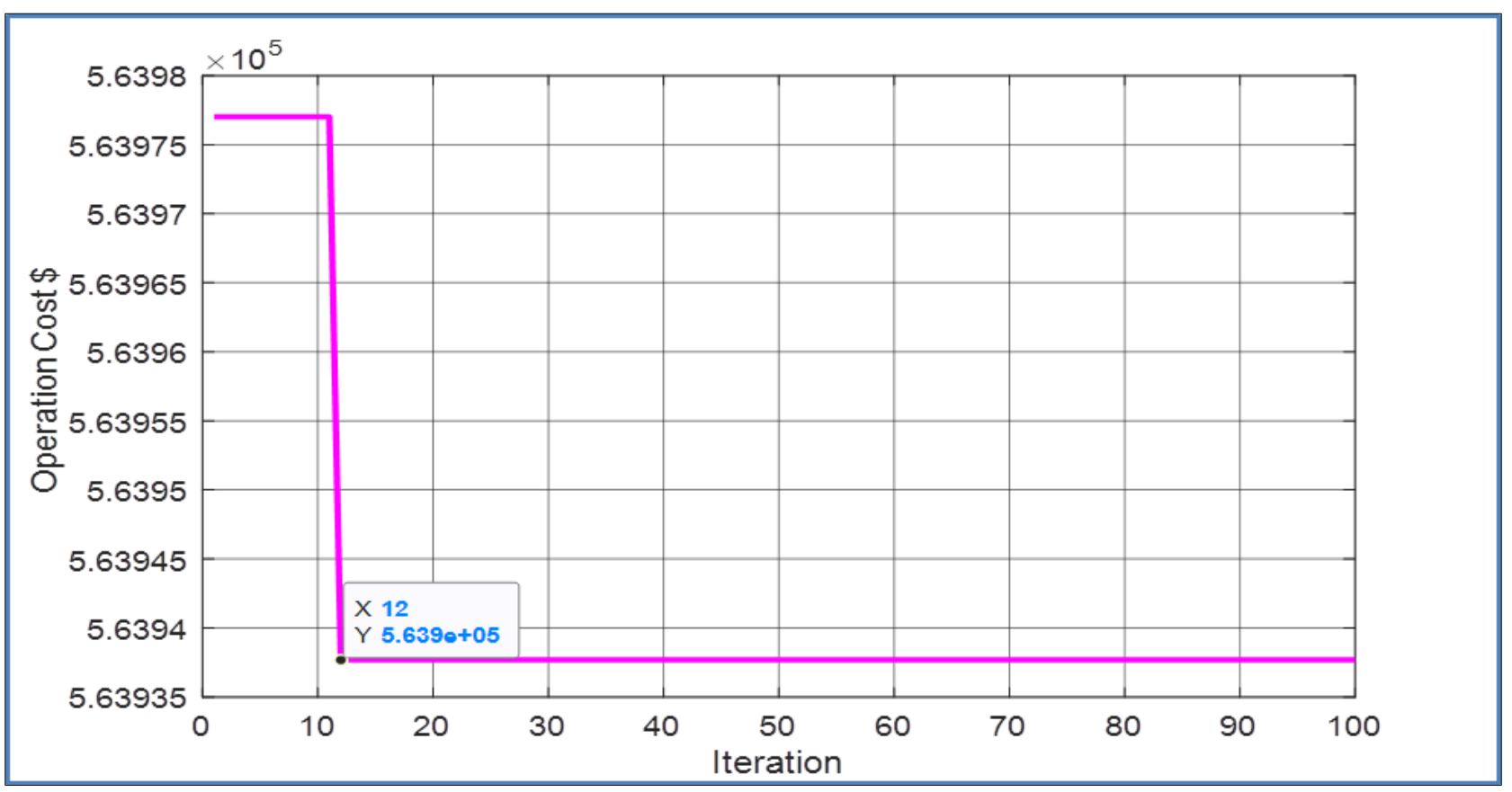

Figure 3. Cost convergence characteristics of 10 units 
Table 4 clarify compares the results of the operating cost of the unit commitment problem solved by different techniques and the Salp Swarm Algorithm [SSA]. Most of these methods have the problem of falling into the local minima .The difference between the total operating cost in [PLEA] and the total operating cost in [SSA] is (40 \$), This difference is due to the selection of the best operation of the units incertain periods of time and the extinguishing of other generating units and the distribution of their loads to units with lower operating costs, which affected the final result of the total operating cost

Table 4. Total operating cost compared the SSA and different methods for 10-unit

\begin{tabular}{c|c}
\hline Method & Total Operation COST(\$/day) \\
\hline LR[17] & 565,673 \\
PL[3] & 564,835 \\
ACSA[19] & 564,049 \\
GA[18] & 566,404 \\
PSOGWO[20] & 565,210 \\
PLEA[25] & 563,977 \\
SSA & $\mathbf{5 6 3 , 9 3 7}$ \\
\hline
\end{tabular}

\subsection{Power System with 26-Units}

The second system is used to check another system that consists of 26 different large generation units. Table 6 lists the unit data and parameters for these units [26]. Table 5 shows the load demand for 24h [26] and Table 8 shows the output power of each generation unit and the scheduling of these units at the time. The results obtained by applying the proposed algorithm Salp Swarm Algorithm is (721182 \$/day) at the number of population 20 and maximum iteration 100.computation time was $(74.89 \mathrm{sec}$.)

Figure 4 shows the cost convergence characteristics of 26 units Table 7 is clarified compares the result obtained from the salp swarm algorithm [SSA] with the other methods this shows there are differences in results and there is improvement and minimizing in the operation cost.
There are some observations are mentioned below to show how the suggested salp chain model and SSA algorithm are successful in solving optimization problems including UCP:

1. SSA algorithm saves the best solution obtained so far and assigns it to the food source variable.

2. The SSA algorithm only updates the position of the leading salp in comparison to the food source.

3. SSA algorithm updates relative positions of follower salps so that they gradually.

4. SSA algorithm uses follower slap movements to avoid local optima.

5. Parameter $\mathrm{c} 1$ is decreased adaptively for iterations, so the SSA algorithm first explores the search space and then exploits it.

6. There is just one key control parameter in the SSA algorithm $c_{1}$.

7. The SSA algorithm is simple, quick to use, and reliable when it comes to finding the best solution.

Table 5. load demand for 26-unit generation

\begin{tabular}{c|ccc}
\hline Hour & LD [MW] & Hour & LD [MW] \\
1 & 1700 & 13 & 2590 \\
2 & 1730 & 14 & 2550 \\
3 & 1690 & 15 & 2620 \\
4 & 1700 & 16 & 2650 \\
5 & 1750 & 17 & 2550 \\
6 & 1850 & 18 & 2530 \\
7 & 2000 & 19 & 2500 \\
8 & 2430 & 20 & 2550 \\
9 & 2540 & 21 & 2600 \\
10 & 2600 & 22 & 2480 \\
11 & 2670 & 23 & 2200 \\
12 & 2590 & 24 & 1840 \\
\hline
\end{tabular}


Table 6. Data and parameters of 26- generation units

\begin{tabular}{|c|c|c|c|c|c|c|c|c|c|c|c|}
\hline unit & $\begin{array}{l}P_{\max } \\
(\mathrm{MW})\end{array}$ & $\begin{array}{l}P_{\text {min }} \\
(\mathrm{MW})\end{array}$ & $\begin{array}{c}a_{g} \\
(\$ / h)\end{array}$ & $\begin{array}{c}\boldsymbol{b}_{\boldsymbol{g}} \\
(\$ / \mathrm{MWh})\end{array}$ & $\begin{array}{c}c_{g} \\
\left(\$ / \mathbf{M W}^{2} h\right.\end{array}$ & $\begin{array}{c}\text { MUT } \\
\text { (h) }\end{array}$ & $\begin{array}{c}\text { MDT } \\
\text { (h) }\end{array}$ & $\begin{array}{c}\text { HSC } \\
\text { (\$) }\end{array}$ & $\begin{array}{c}\text { CSC } \\
\text { (\$) }\end{array}$ & $\begin{array}{c}\text { CSH } \\
\text { (h) }\end{array}$ & $\begin{array}{c}\text { In.stat } \\
\text { (h) }\end{array}$ \\
\hline 1 & 400 & 100 & 311.9102 & 7.5031 & 0.0019 & 8 & 5 & 500 & 500 & 10 & 10 \\
\hline 2 & 400 & 100 & 310.0021 & 7.4921 & 0.0019 & 8 & 5 & 500 & 500 & 10 & 10 \\
\hline 3 & 350 & 140 & 177.0575 & 10.8616 & 0.0015 & 8 & 5 & 300 & 300 & 8 & 10 \\
\hline 4 & 197 & 68.95 & 260.176 & 23.2 & 0.0026 & 5 & 4 & 200 & 200 & 8 & -4 \\
\hline 5 & 197 & 68.95 & 259.649 & 23.1 & 0.0026 & 5 & 4 & 200 & 200 & 8 & -4 \\
\hline 6 & 197 & 68.95 & 259.131 & 23 & 0.0026 & 5 & 4 & 200 & 200 & 8 & -4 \\
\hline 7 & 155 & 54.25 & 143.5972 & 10.7583 & 0.0049 & 5 & 3 & 150 & 150 & 6 & 5 \\
\hline 8 & 155 & 54.25 & 134.3179 & 10.7367 & 0.0048 & 5 & 3 & 150 & 150 & 6 & 5 \\
\hline 9 & 155 & 54.25 & 143.0288 & 10.7154 & 0.0047 & 5 & 3 & 150 & 150 & 6 & 5 \\
\hline 10 & 155 & 54.25 & 142.7348 & 10.694 & 0.0046 & 5 & 3 & 150 & 150 & 6 & 5 \\
\hline 11 & 100 & 25 & 218.7752 & 18.2 & 0.006 & 4 & 2 & 70 & 70 & 4 & -3 \\
\hline 12 & 100 & 25 & 218.335 & 18.1 & 0.0061 & 4 & 2 & 70 & 70 & 4 & -3 \\
\hline 13 & 100 & 25 & 217.8952 & 18 & 0.0062 & 4 & 2 & 70 & 70 & 4 & -3 \\
\hline 14 & 76 & 15.2 & 81.6259 & 13.4073 & 0.0093 & 3 & 2 & 50 & 50 & 3 & 3 \\
\hline 15 & 76 & 15.2 & 81.4681 & 13.3805 & 0.0091 & 3 & 2 & 50 & 50 & 3 & 3 \\
\hline 16 & 76 & 15.2 & 81.298 & 13.3538 & 0.0089 & 3 & 2 & 50 & 50 & 3 & 3 \\
\hline 17 & 76 & 15.2 & 81.1364 & 13.3272 & 0.0088 & 3 & 2 & 50 & 50 & 3 & 3 \\
\hline 18 & 20 & 4 & 118.8206 & 37.8896 & 0.0143 & 0 & 0 & 20 & 20 & 2 & -1 \\
\hline 19 & 20 & 4 & 118.4576 & 37.777 & 0.0136 & 0 & 0 & 20 & 20 & 2 & -1 \\
\hline 20 & 20 & 4 & 118.1083 & 37.6637 & 0.0126 & 0 & 0 & 20 & 20 & 2 & -1 \\
\hline 21 & 20 & 4 & 117.7551 & 37.551 & 0.012 & 0 & 0 & 20 & 20 & 2 & -1 \\
\hline 22 & 12 & 2.4 & 24.8882 & 26.0611 & 0.0285 & 0 & 0 & 0 & 0 & 1 & -1 \\
\hline 23 & 12 & 2.4 & 24.7605 & 25.9318 & 0.0284 & 0 & 0 & 0 & 0 & 1 & -1 \\
\hline 24 & 12 & 2.4 & 24.6382 & 25.8027 & 0.028 & 0 & 0 & 0 & 0 & 1 & -1 \\
\hline 25 & 12 & 2.4 & 24.411 & 25.6753 & 0.0265 & 0 & 0 & 0 & 0 & 1 & -1 \\
\hline 26 & 12 & 2.4 & 24.3891 & 25.5472 & 0.0253 & 0 & 0 & 0 & 0 & 1 & -1 \\
\hline
\end{tabular}

Table 7. The total cost produced by the SSA and different methods for 26-unit

\begin{tabular}{c|c}
\hline Method & Total Cost (\$lday) \\
ILR[22] & 725996 \\
QBPSO[23] & 726037 \\
BPSO[23] & 721965 \\
SSA & $\mathbf{7 2 1 1 8 2}$ \\
\hline
\end{tabular}




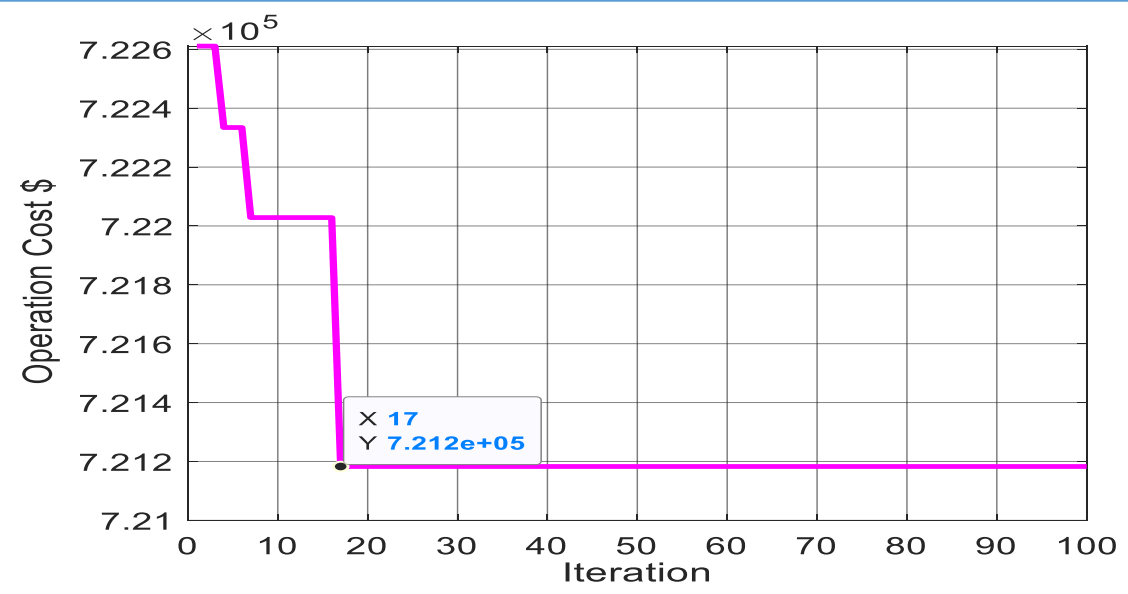

Figure 4. Cost convergence characteristics of 26 units

Table 8. output power and scheduling of the system 26 -unit generation for $24 \mathrm{~h}$

\begin{tabular}{|c|c|c|c|c|c|c|c|c|c|}
\hline $\mathrm{H}$ & U1 & $\mathrm{U} 2$ & U3 & $\mathrm{U} 4$ & U5 & U6 & U7 & $\mathrm{U} 8$ & U9 \\
\hline 1 & 400 & 400 & 331.1455 & 0 & 0 & 0 & 114.6412 & 118.3165 & 122.5693 \\
\hline 2 & 400 & 400 & 344.2678 & 0 & 0 & 0 & 118.7638 & 122.4906 & 126.8139 \\
\hline 3 & 400 & 400 & 333.42 & 0 & 0 & 0 & 115.3558 & 119.04 & 123.305 \\
\hline 4 & 400 & 400 & 336.7443 & 0 & 0 & 0 & 116.4002 & 120.0975 & 124.3803 \\
\hline 5 & 400 & 400 & 350 & 0 & 0 & 0 & 122.2489 & 126.0192 & 130.4022 \\
\hline 6 & 400 & 400 & 350 & 0 & 0 & 0 & 140.5688 & 144.5676 & 149.2643 \\
\hline 7 & 400 & 400 & 350 & 0 & 0 & 0 & 155 & 155 & 155 \\
\hline 8 & 400 & 400 & 350 & 68.95 & 68.95 & 68.95 & 155 & 155 & 155 \\
\hline 9 & 400 & 400 & 350 & 68.95 & 68.95 & 68.95 & 155 & 155 & 155 \\
\hline 10 & 400 & 400 & 350 & 68.95 & 68.95 & 80.9 & 155 & 155 & 155 \\
\hline 11 & 400 & 400 & 350 & 70.7501 & 90.7972 & 110.4528 & 155 & 155 & 155 \\
\hline 12 & 400 & 400 & 350 & 68.95 & 68.95 & 70.9 & 155 & 155 & 155 \\
\hline 13 & 400 & 400 & 350 & 68.95 & 68.95 & 70.9 & 155 & 155 & 155 \\
\hline 14 & 400 & 400 & 350 & 68.95 & 68.95 & 68.95 & 155 & 155 & 155 \\
\hline 15 & 400 & 400 & 350 & 68.95 & 73.1313 & 92.7187 & 155 & 155 & 155 \\
\hline 16 & 400 & 400 & 350 & 68.95 & 84.9086 & 104.5414 & 155 & 155 & 155 \\
\hline 17 & 400 & 400 & 350 & 68.95 & 68.95 & 68.95 & 155 & 155 & 155 \\
\hline 18 & 400 & 400 & 350 & 68.95 & 68.95 & 68.95 & 155 & 155 & 155 \\
\hline 19 & 400 & 400 & 350 & 68.95 & 68.95 & 68.95 & 155 & 155 & 155 \\
\hline 20 & 400 & 400 & 350 & 68.95 & 68.95 & 68.95 & 155 & 155 & 155 \\
\hline 21 & 400 & 400 & 350 & 68.95 & 68.95 & 80.9 & 155 & 155 & 155 \\
\hline 22 & 400 & 400 & 350 & 68.95 & 68.95 & 68.95 & 155 & 155 & 155 \\
\hline 23 & 400 & 400 & 350 & 0 & 0 & 68.95 & 155 & 155 & 155 \\
\hline 24 & 400 & 400 & 350 & 0 & 0 & 0 & 138.1262 & 142.0945 & 146.7494 \\
\hline
\end{tabular}




\begin{tabular}{|c|c|c|c|c|c|c|c|c|c|}
\hline $\mathrm{H}$ & U10 & U11 & U12 & U13 & U14 & U15 & U16 & U17 & U18 \\
\hline 1 & 127.5276 & 0 & 0 & 25 & 15.2 & 15.2 & 15.2 & 15.2 & 0 \\
\hline 2 & 131.8639 & 0 & 0 & 25 & 15.2 & 15.2 & 15.2 & 15.2 & 0 \\
\hline 3 & 128.2792 & 0 & 0 & 25 & 0 & 15.2 & 15.2 & 15.2 & 0 \\
\hline 4 & 129.3777 & 0 & 0 & 25 & 0 & 15.2 & 15.2 & 15.2 & 0 \\
\hline 5 & 135.5297 & 0 & 0 & 25 & 15.2 & 15.2 & 15.2 & 15.2 & 0 \\
\hline 6 & 154.7992 & 0 & 25 & 25 & 15.2 & 15.2 & 15.2 & 15.2 & 0 \\
\hline 9 & 155 & 79.9895 & 86.3296 & 92.831 & 76 & 76 & 76 & 76 & 0 \\
\hline 10 & 155 & 100 & 100 & 100 & 76 & 76 & 76 & 76 & 0 \\
\hline 11 & 155 & 100 & 100 & 100 & 76 & 76 & 76 & 76 & 0 \\
\hline 12 & 155 & 100 & 100 & 100 & 76 & 76 & 76 & 76 & 0 \\
\hline 13 & 155 & 100 & 100 & 100 & 76 & 76 & 76 & 76 & 0 \\
\hline 17 & 155 & 83.3943 & 89.6565 & 96.0992 & 76 & 76 & 76 & 76 & 0 \\
\hline 18 & 155 & 76.5846 & 83.0026 & 89.5628 & 76 & 76 & 76 & 76 & 0 \\
\hline 19 & 155 & 66.3701 & 73.0218 & 79.7581 & 76 & 76 & 76 & 76 & 0 \\
\hline 20 & 155 & 83.3943 & 89.6565 & 96.0992 & 76 & 76 & 76 & 76 & 0 \\
\hline 21 & 155 & 100 & 100 & 100 & 76 & 76 & 76 & 76 & 0 \\
\hline 22 & 155 & 59.5604 & 66.3679 & 73.2217 & 76 & 76 & 76 & 76 & 0 \\
\hline 23 & 155 & 25 & 25 & 25 & 65.3397 & 68.3919 & 71.0298 & 74.0886 & 0 \\
\hline 24 & 152.2299 & 0 & 25 & 25 & 15.2 & 15.2 & 15.2 & 15.2 & 0 \\
\hline
\end{tabular}

\begin{tabular}{c|cccccccc}
\hline $\mathrm{H}$ & $\mathrm{U} 19$ & $\mathrm{U} 20$ & $\mathrm{U} 21$ & $\mathrm{U} 22$ & $\mathrm{U} 23$ & $\mathrm{U} 24$ & $\mathrm{U} 25$ & $\mathrm{U} 26$ \\
\hline 1 & 0 & 0 & 0 & 0 & 0 & 0 & 0 & 0 \\
2 & 0 & 0 & 0 & 0 & 0 & 0 & 0 & 0 \\
3 & 0 & 0 & 0 & 0 & 0 & 0 & 0 & 0 \\
4 & 0 & 0 & 0 & 2.4 & 0 & 0 & 0 & 0 \\
5 & 0 & 0 & 0 & 0 & 0 & 0 & 0 & 0 \\
6 & 0 & 0 & 0 & 0 & 0 & 0 & 0 & 0 \\
7 & 0 & 4 & 0 & 0 & 2.4 & 2.4 & 0 & 2.4 \\
8 & 0 & 0 & 0 & 0 & 0 & 0 & 0 & 0 \\
9 & 0 & 0 & 0 & 0 & 0 & 0 & 0 & 0 \\
10 & 0 & 0 & 0 & 0 & 0 & 2.4 & 2.4 & 2.4 \\
11 & 4 & 4 & 4 & 2.4 & 2.4 & 2.4 & 2.4 & 2.4 \\
12 & 0 & 0 & 0 & 0 & 0 & 2.4 & 2.4 & 2.4 \\
13 & 0 & 0 & 0 & 0 & 0 & 2.4 & 2.4 & 2.4 \\
14 & 0 & 0 & 0 & 0 & 0 & 0 & 0 & 0 \\
15 & 0 & 0 & 4 & 2.4 & 2.4 & 2.4 & 2.4 & 2.4 \\
16 & 0 & 4 & 4 & 2.4 & 2.4 & 2.4 & 2.4 & 2.4 \\
17 & 0 & 0 & 0 & 0 & 0 & 0 & 0 & 0 \\
18 & 0 & 0 & 0 & 0 & 0 & 0 & 0 & 0 \\
19 & 0 & 0 & 0 & 0 & 0 & 0 & 0 & 0 \\
20 & 0 & 0 & 0 & 0 & 0 & 0 & 0 & 0 \\
21 & 0 & 0 & 0 & 0 & 0 & 2.4 & 2.4 & 2.4 \\
22 & 0 & 0 & 0 & 0 & 0 & 0 & 0 & 0 \\
23 & 0 & 4 & 0 & 0 & 0 & 0 & 2.4 & 0 \\
24 & 0 & 0 & 0 & 0 & 0 & 0 & 0 & 0 \\
\hline
\end{tabular}




\section{Conclusions}

An algorithm was presented to solve the optimum unit commitment problem. From Table 4 and Table 8 the comparison between the proposed algorithm and the other shows differences in total operation cost, since artificial intelligence techniques are more effective than traditional approaches. The reasons for this superiority, as well as the parameters settings and system coding, are far more straightforward than old techniques. Moreover, some algorithms have disadvantages to the local minima solution. The optimization process was based on the Slap swarm algorithm. The different operational and transition constraints were taken into consideration. The proposed algorithm was applied to the power system of a 10-unit and 26-unit simulation over a 24-hour time horizon, and the operating cost was kept to a minimum. The results revealed that the Salp Swarm Algorithm [SSA] is more stable and capable of finding a solution, and it's able to solve the large power system. Furthermore, the proposed algorithm succeeded in satisfying all the restrictions of the UCP.

\section{Conflict of interest}

The authors declare that there are no conflicts of interest regarding the publication of this manuscript.

\section{Abbreviations}

SSA

Salp Swarm Algorithm

$\mathrm{UCP}$

Unit Commitment Problem

$\mathrm{PC}_{\text {total }}:$ total

total production cost

$\mathrm{T}$

N

K

g

$f_{g k}$

$U_{g k}$ $p_{g k}$

$S T C_{g k}$

$S D C_{g k}$

$\mathrm{a}_{\mathrm{g}}, \mathrm{b}_{\mathrm{g}}$ and $\mathrm{c}_{\mathrm{g}}$

$H S C_{g}$

${ } S C_{\mathrm{g}}$

$\mathrm{CSH}_{\mathrm{g}}$

$M D T_{\mathrm{g}}$

$M U T_{\mathrm{g}}$

$\mathrm{T}_{\mathrm{g}}^{\mathrm{on}}$

$\mathrm{T}_{\mathrm{g}}^{\text {off }}$

$\mathrm{P}_{\mathrm{gk}}$

$\mathrm{LD}_{\mathrm{k}}$

$\mathrm{P}_{\mathrm{g}}^{\max \text {. }}$

$\mathrm{P}_{\mathrm{g}}^{\min .}$

$\mathrm{SR}_{\mathrm{k}}$

$\mathrm{X}_{\mathrm{j}}^{1}$

$F_{j}$

$u b_{j}$ and $l b_{j}$

$c_{2}, c_{3}$

$X_{j}^{i}$

$t^{*}$

$v_{0}$

itermax

$\mathrm{t}$
$0=\mathrm{OFF})$.

output power from generator $\mathrm{g}$ at time $\mathrm{k}$

the start-up cost of generator $\mathrm{g}$ at time $\mathrm{k}$

shut-down cost of generator $g$ at time $\mathrm{k}$

fuel cost coefficients of generator $\mathrm{g}$

the hot start-up cost of generator $\mathrm{g}$.

the cold start-up cost of generator $\mathrm{g}$

Cold-start hour generator $\mathrm{g}$.

minimum downtime

minimum uptime

time of the unit $g$ is continuously ON.

time of the unit $\mathrm{g}$ is continuously OFF.

generator's output power

load demand at time $\mathrm{k}$

maximum power capacity of generator $\mathrm{g}$

minimum power capacity of .generator $\mathrm{g}$

spinning reserve of the power system at time $\mathrm{k}$

position of the first salp (leader) in $\mathrm{j}$-dimension

food source position in $\mathrm{j}$ dimension

upper and lower boundaries in .j-dimension respectively random numbers in the interval $[0,1]$

position of $\mathrm{i}$-th follower salps in .jth dimensions

time

initial velocity

maximum iterations

Current iteration 
ILR Improved Lagrangian

Relaxation

QBPSO Quantum Inspired Binary

Particle Swarm Optimization

BPSO Binary Particle Swarm

Optimization

\section{References}

1. Jizhong Zhu,(2015) "Optimization of Power System Operation". $2^{\text {nd }}$ ed., PP.253

2. Hobbs BF, Rothkopf MH, O'Neill RP, Chao H.(2001). "The next generation of electric power unit commitment models". Springer Science\& Business Media, llc;.

3. A. M. Elsayed, A. M. Maklad, and S. M. Farrag,(2018)."A new priority list unit commitment method for large-scale power systems" $19^{\text {th }}$ International Middle-East Power Systems Conference, MEPCON 2017 - Proceedings, 2018, pp. 359-367.

4. T. Senjyu, K. Shimabukuro, K. Uezato, and T. Funabashi,(2003) "A fast technique for unit commitment problem by extended priority list" IEEE Trans. Power Syst., vol. 18 , no. 2, pp. 882-888.

5. W. L. Snyder Jr., H. D. Powell Jr., and J. C. Rayburn,(1987) "Dynamic programming approach to unit commitment" IEEE Trans. on Power Apparatus and Systems, Vol. PAS-2, pp. 339-350.

6. S. Virmani, E. C. Adrian, K. Imhof, and S. Mukherjee,(1989) "Implementation of a Lagrangian relaxation based unit commitment problem" IEEE Trans. Power Syst., vol. 4, no. 4, pp. 1373-1380.

7. F. Zhuang and F. D. Galiana,(1988)"Toward a more rigorous and practical unit commitment by Lagrangian relaxation" IEEE Trans. on Power Systems, Vol. 3, No. 2, pp. 763770.
8. A. I. Cohen and M. Yoshimura,(1983) "A branch-and-bound algorithm for unit commitment" IEEE Trans. on Power Apparatus and Systems, Vol .PAS-102, pp. 444-451.

9. G. W. Chang, Y. D. Tsai, C. Y. Lai, and J. S. Chung,(2055) "A practical mixed integer linear programming based approach for unit commitment". pp. 221225.

10. S. A. Kazarlis, A. G. Bakirtzis, and V. Petridis,(1996) "A genetic algorithm solution to the unit commitment problem" IEEE Trans. on Power Systems, Vol. 11, No. 1, pp. 83-92.

11. K. A. Juste, H. Kita, E. Tanaka, and J. Hasegawa,(1999). "An evolutionary programming solution to the unit commitment problem" IEEE Trans .on Power Systems, vol. 14, pp. 1452-1459.

12. D. N. Simopoulos, S. D. Kavatza, and C. D. Vournas,(2006) "Unit commitment by an enhanced simulated annealing algorithm" in IEEE Transactions on 114 Power Systems, vol. 21, no. 1, pp. 68-76.

13. B. Zhao, C. X. Guo, B. R. Bai, and Y. J. Cao,(2006) "An improved particle swarm optimization algorithm for unit commitment" Electrical Power \& Energy Systems, Vol. 28, Issue 7, pp. 482-490.

14. Aditya P. and Kuldeep K. Swankar.(2013) "Genetic algorithm using to the solution of unit commitment" International Journal of Engineering Trends and Technology (IJETT).

15. S. Mirjalili, A.H. Gandomi, S.Z. Mirjalili, S. Saremi, H. Faris, S.M.Mirjalili.(2017) "Salp swarm algorithm: A bio-inspired optimizer for engineering design problems". Advances in Engineering Software, vol.114, pp. 163-191.

16. A. J. Wood, B. F. Wollenberg, and G. B. Sheblé, (2014)"Power

generation, 
operation, and control". $3^{\text {rd }}$ ed. Hoboken, New Jersey: John Wiley \& Sons,

17. Singhal PK.(2011) "Generation scheduling methodology for thermal units using Lagrangian relaxation". Nirma University International Conference on Engineering: Current Trends in Technology. pp. 1-6.

18. Damousis IG, Bakirtzis AG, Dokopoulos PS.(2004) "A solution to the unit commitment problem using an integer coded genetic algorithm". IEEE Trans Power System. pp:1165-72

19. Sum-in T, Ongsakul W. (2003)"Ant colony search algorithm for unit commitment". In: IEEE International Conference on Industrial Technology, Maribor, Slovenia. p. 72-7.

20. Kamboj VK.(2016). "A novel hybrid PSO-GWO approach for unit commitment problem". Neural Comput Appl [Internet]. Aug;27(6):1643-55.Available from: https://doi.org/10.1007/s00521-015-1962$\underline{4}$

21. Zhao B, Guo CX, Bai BR, Cao YJ. "An improved particle swarm optimization algorithm for unit commitment". Int $\mathrm{J}$ Electr Power Energy Syst [Internet]. Available from: https://www.sciencedirect.com/science/arti cle/pii/S014206150600055X

22. W. Ongsakul and N. Petcharaks,(2005) "Ramp rate constrained unit commitment by improved adaptive Lagrangian relaxation" Int. Energy J., vol. 6,

23. Ali A. Ismail.(2019) "Operation cost reduction in unit commitment problem using improved quantum binary PSO algorithm". Middle Technical University.

24. H. Faris, S. Mirjalili, I. Aljarah, M. Mafarja and Ali A. Heidari "Salp Swarm Algorithm: Theory, Literature Review, and
Application in Extreme Learning Machines". pp. [189].

25. D. Srinivasan and J. Chazelas,(2004) "A priority list based evolutionary algorithm to solve large scale unit commitment problem" International Conference on Power System Technology. Power Con 2004, pp. 1746-1751.

26. K. Chandrasekaran and S. P. Simon, "Binary/real coded particle swarm optimization for unit commitment problem," in 2012 International Conference on Power, Signals, Controls and Computation, EPSCICON References 115 ,Thrissur, Kerala, 2012, pp. 1-6. 